\title{
EL SISTEMA PROBATORIO MEDIEVAL DE LOS GERMANOS VISTO POR HISTORIADORES ALEMANES DEL DERECHO DEL SIGLO XIX Y DE COMIENZOS DEL SIGLO XX *
}

[The Medieval System of Proofs of Germanic Peoples Studied by Germans Historians of Law of Nineteenth and Early Twentieth Century]

\author{
Luis Rojas DONAT** \\ Universidad del Bío-Bío, Chile
}

\begin{abstract}
RESUMEN
El trabajo se articula en torno al sistema probatorio germánico analizado por algunos historiadores alemanes del siglo XIX y comienzos del XX, y se centra en el análisis de la "Friedlosigkeit", que podría traducirse como "supresión o exclusión fuera de la paz". La polémica buscó superar la impresión bárbara y primitiva que provocaba entonces el derecho penal germánico ("Strafrecht"), interpretando desde una lógica no romana, de acuerdo a un desarrollo orgánico del derecho continuamente readaptado a la organización de la sociedad medieval y sus necesidades. Intentando probar la existencia de un derecho penal germánico independiente del derecho penal romano, el punto consistió en determinar si el derecho a la venganza ("Fehderecht") procedía de la primitiva "libertad germánica" ("germanische Freiheit") o era un derecho
\end{abstract}

\begin{abstract}
This work deals with the Germanic evidence disclosure system, as analyzed by some German Historians of the $19^{\text {th }}$ and early $20^{\text {th }}$ Century, and focuses on the analysis of Friedlosigkeit, which could be translated as "outlawry". The controversy attempted to overcome the impression of the Germanic criminal law (Strafrecht) of that era as being barbaric and primitive, by interpreting it from a non-Roman logic according to an organic development of the law continuously re-adapted to the organization of the medieval society and its needs. This article attempts to prove that there is a Germanic criminal law independent from the Roman criminal law, the point was determining if the right to revenge (Fehderecht) came from the primitive "Germanic freedom" (germanische Freiheit) or if it was a
\end{abstract}

* Este trabajo forma parte de un proyecto mayor titulado "Alteridad jurídica en el Occidente medieval: las ordalías”, financiado por FONDECYT, No 1110474 (2011-2012).

** Profesor titular de Historia Medieval en la Universidad del Bío-Bío y en la Universidad de Concepción. Dirección postal: Itata, 253, Depto. 401, Chillán, Chile. Correo electrónico: lsrojas.donat@gmail.com 
legitimado por el "orden estatal" de la comunidad ("Volksgenossenschaft").

Palabras Clave

Venganza - "Friedlosigkeit" - Derecho Germánico. Revenge - Germanic Law. right legitimated by the "state order" of the community (Volksgenossenschaft). Law.

RECIBIDO el 16 de mayo y ACEPTADO el 26 de julio de 2012

\section{LA DOCTRINA DEL “ESTADO NATURAL” DE LA ALTA EDAD MEDIA}

La idea del "estado natural” es una teoría interpretativa, un paradigma, un conjunto de ideas ordenadas a través de una lógica o, si se quiere, un marco previo de referencias para analizar los hechos del pasado. Tal como suele suceder con el pasado mismo, la teoría mediante la cual se interpreta ese pretérito responde también a su condicionante entorno histórico.

Interesa presentar el contexto del debate intelectual, típicamente decimonónico, cargado de nacionalismo, que entrabó a los historiadores alemanes, que intentaban destacar el peculiar sentido de justicia -y no barbarie- de los germanos, y los historiadores franceses que buscaban demostrar la fuerte romanización que ya tenía la población galo-romana en la época de las invasiones germánicas, frente a las costumbres primitivas que estos pueblos introdujeron en la Galia. Ello había de tener evidentes consecuencias en la historiografía decimonónica francesa dedicada a la historia de la justicia, puesto que los historiadores del derecho sintieron muy poco atractivo por el período medieval. Estando vigente el derecho a la venganza, esa institución común de los pueblos germánicos ("eine gemeingermanische Institution"), consideraban que no solamente no existía sistema judicial, sino todavía más, afirmaban la ausencia de un auténtico "Estado de derecho". Ello permite explicar que los franceses hayan dejado a sus colegas alemanes la tarea de explicar la época del supuesto "orden feudal” heredado de sus ancestros, los francos, período al que consideraban una "anarquía" judicial, la "failure of the State”, según la expresión de Chris Wickham ${ }^{1}$.

Las teorías acerca del origen del orden jurídico medieval, y al interior del mismo, el derecho a la venganza, distanció a los historiadores franceses que consideraron completamente infructuoso siquiera analizar los inicios del sistema jurídico medieval, ya que simplemente la venganza era en definitiva antinómica con cualquier estado de derecho.

Planteadas así las cosas, la historiografía francesa concentró su mirada en la época posterior al siglo XIII, momento en que las instituciones judiciales comenzaron a tener una cierta forma de organización a nivel eclesiástico, pero también en el ámbito municipal junto a la creación de los tribunales reales. En

${ }^{1}$ Wickham, Chris, Early Medieval Italy. Central Power and Local Society. 400-1000 (London, 1981), cap. $7^{\text {o. }}$. 
este ambiente histórico, el progreso que se aprecia en los procedimientos usados ante los juzgados alcanzó varios aspectos: mejoras en el sistema de pruebas, avances en la forma de llevar la investigación que pasó del procedimiento acusatorio al inquisitorio, y el surgimiento de los procesos extraordinarios basados en el secreto y la aplicación de la tortura ${ }^{2}$. Por último, en el siglo XIII aparecen ediciones de textos legales acompañados de eruditos comentarios del derecho de costumbres, y se difunde el derecho comentado por los juristas, es decir, un derecho sabio elaborado por peritos.

Era, pues, más digno entrar en la Edad Media clásica, momento en que, se decía, habría nacido el derecho. Justamente, en esta época el sistema judicial se impone sobre el cuerpo social, dándole al juez una herramienta fundamental a la hora de juzgar, esto es, que su convicción se formará, desde ahora, en base a una investigación racional. Por eso, en los procedimientos judiciales se perseguirán tres objetivos esenciales: establecer la verdad del crimen, determinar su autor y, por último, aplicarle la sanción que merece con referencia a un código vigente, todo ello fundado en la convicción del juez.

El paradigma historiográfico que se impuso en la segunda mitad del siglo XIX fue este: la época germánica, momento moral del ser humano todavía próximo al estado natural y gobernado por el instinto, se prolonga en la siguiente sociedad feudal, caracterizada por la incapacidad que tuvo el derecho objetivo -las leyes escritas- de ganarle a la preponderancia del derecho subjetivo -costumbres-, y de tal situación se deducía que durante la Edad Media no pudo existir un orden jurídico propiamente tal.

\section{LA HISTORIOGRAFÍA ALEMANA}

El estudio de la generación del derecho medieval surgido de la transformación que el derecho romano sufrió en el contacto con culturas indígenas, entre las que destaca el derecho consuetudinario de los germanos, ha sido un tema que motivó una intensa reflexión entre los estudiosos alemanes ${ }^{3}$. El estímulo se produjo con motivo de la invasión de Napoleón, y la decisión de éste, después de la batalla de Jena, de implantar en Alemania el código civil francés. Ello provocó una histórica polémica entre Anton Friedrich Thibaut (1772-1840) con su ensayo De la necesidad de un derecho civil general para Alemania, y el texto de Friedrich Karl von Savigny (1779-1861) titulado De la vocación de nuestro tiempo para la codifcación y la ciencia del derecho ${ }^{4}$. Thibaut era partidario de crear un código civil para

${ }^{2}$ Petit-Dutaillis, Charles, Documents nouveaux sur les mours populaires et le droit de vengeance dans les Pays Bas du XVe siècle (Paris, 1908; reimpresión en Slatkine Reprints, Genève, 1975); Bongert, Yvonne, Recherches sur les cours lä̈ques du Xe au XIII siècle (Paris, 1944); DuBY, Georges, Recherches sur l'évolution des institutions judiciaires pendants le Xe et le XI siècle dans le Sud de la Bourgogne”, en Le Moyen Âge, 52 (1946), pp. 149-95; ibíd.; 53 (1947), pp. 15-38.

${ }^{3}$ Moeglin, Jean-Marie Le droit de vengeance chez les historiens du droit au Moyen Âge (XIXe$X X^{e}$ siècles), en BARThélemy, D. - Bougard, F. - JAN, R. (directores), La vengeance 400-1200 (École Française de Rome, 2006 pp. 101-148.

${ }^{4}$ ThIBAUT, Anton Friedrich, Über die Nothwendigkeit eines allgemeinen bürgerlichen Rechts 
Alemania, tal como ya se había hecho en Francia y en Austria. El establecimiento de un derecho nacional civil alemán mediante la codificación, debería reflejar el producto de una suerte de "razón eterna", como decían los ilustrados franceses. En cambio, Savigny declaraba que el derecho no podía "crearse", ya que lo concebía como un conjunto de normas que surgían de un proceso lento de acuerdo a la evolución histórica de la misma sociedad. Este acervo de lenguaje, costumbres y cultura, constituía un producto del "espíritu del pueblo" ("Volksgeist") que no debía ni podía borrarse de una plumada. No era el momento ni había suficiente formación jurídica para realizar esta tarea ${ }^{5}$.

Con motivo de esta polémica, en 1815, F. K. von Savigny, Karl Friedrich Eichhorn (1781-1854) y Jacob Grimm (1785-1863) crean la Escuela histórica del Derecho con la fundación de la "Revista de la ciencia histórica del derecho" (Zeitschrift für geschichtliche Rechtwissenschaft), buscando asentar el derecho de su época en el antiguo derecho elaborado por los diferentes cuerpos de la sociedad en su evolución histórica. Con la desaparición de esta revista en 1850, Adolf August Friedrich Rudorff, discípulo de Savigny, funda en 1861 la "Revista de Historia del Derecho" (Zeitschrift für Rechtgeschichte) evidenciando con su nombre la ruptura que se produjo entre los jóvenes historiadores germanistas y los adultos historiadores romanistas, cuyos derroteros siguieron caminos distintos ${ }^{6}$. Con todo, la superioridad insuperable de la intelectualidad alemana, a partir del siglo XIX quedó de manifiesto frente a la debilidad de la erudición francesa. Contribuyó el manuscrito de la Germania de Tácito, descubierto en Hersfeld a mediados del siglo XV, que agregaría importantes informaciones acerca de las costumbres germanas ${ }^{7}$. Ello permitió a los historiadores alemanes descubrir que sus ancestros germánicos no eran barbaros primitivos, como sí creían los franceses ${ }^{8}$.

Con las precarias posibilidades documentales de la época, Eichhorn veía en la constitución de la "villa" franca (forma de asentamiento rural de la alta Edad Media) el resultado directo de la conquista de la civilización romana por los ger-

für Deutschland (Berlin, 1814); SAVIGNY, Friedrich Karl von, Vom Berufunserer Zeit für Gesetzgebung und Rechtswissenschaft (Berlin, 1814).

${ }^{5}$ Dilcher, G. - Kern, B. R., Die juristische Germanistik des 19. Jahrhunderts und die Fachtradition der Deutschen Rechtsgeschichte, en Zeitschrift für Rechtsgeschischt, germ. Abt. , 101 (1984), pp. 1-46.

${ }^{6} \mathrm{La}$ Zeitschrift für Rechtsgeschichte tuvo su continuadora a partir de 1880 en la Zeitschrift der Savigny-Stiftung für Rechtsgeschichte, dividida en tres secciones: Romanistiche Abteilung, Kanonistische Abteilung y Germanistische Abteilung; cada sección constituye una revista independiente. Vèase: Dilcher-Kern, Die Juristische Germanistik, cit. (n. 5), n. 28.

${ }^{7}$ Paniagua Aguilar, David, El panorama literario técnico-científico en Roma (siglos I-II D.C.), "et docere et delectare", en Acta Salmanticensia: Estudios filológicos, 312 (Universidad de Salamanca, 2006), pp. 177-87.

${ }^{8}$ Por ejemplo, Guizot, François, Cours d'histoire moderne. Histoire de la civilisation en France depuis la chute de l'Empire romain jusqu'en 1789 (Paris, 1829-1832), 5 vols. Véase especialmente el tomo I, pp. 343-50. También Ernest Glasson publicó en 1888, en Paris, el segundo tomo de la monumental Histoire du droit et des institutions de la France, y véanse sus pp. 84-85. En 1886, MonoD, Gabriel publicó Les aventures de Sichaire en la Revue Historique, 31 (1886), pp. 259-90 (véanse las pp. 266 y 285-286). Lo mismo DucoudraY, Gustave, Les origines du Parlement de Paris et la Justice aux XIII'-XIV siècles (Paris, 1902), pp. 325-326. 
manos, es decir, la imposición de una capa dominante germánica sobre un sustrato de "sometidos" ("Untertanen") de origen romano, libres o esclavos, establecidos o no. En esta unidad territorial, donde se aprecia la coexistencia, se demostraba también -según él-, el aporte germánico en la ocupación del espacio?.

Evidentemente, se buscaba superar la primera y simplista impresión que provoca el sistema de pruebas del derecho germánico, esto es, una barbarie en estado puro. Ello puede explicarse por la inevitable comparación que suele hacerse con el derecho romano y su propio sistema probatorio, el que, sin duda, conocemos $-\mathrm{y}$ reconocemos- mejor porque es el antecesor de nuestro actual sistema judicial. Por cierto, puesto así al lado del romano, el sistema germánico se muestra primitivo y bárbaro, distorsionando gravemente la mirada del historiador. Desde luego, esta perversa comparación no hace más que impedir la apreciación de la lógica interna del sistema probatorio germánico en su propia especificidad y, todavía más, su particular mentalidad adecuada al estadio cultural.

\section{Karl August Rogge.}

Rogge escribe en 1820 un libro que impactaría por la reivindicación hecha a los germanos ${ }^{10}$. Desarrollando una tesis cuya modernidad causaría sorpresa, en los primeros dos capítulos, Rogge estudia la que cree "verdadera naturaleza" de los procedimientos judiciales en los reinos germánicos ("bárbaros”). El punto de partida es fundamental, pues advierte que el error de perspectiva al apreciar el sistema judicial de los germanos, es hacerlo desde el vigente entonces en Alemania, heredero del proceso romano fundado en un sistema de pruebas racionales. Abandonando esta comparación se puede encontrar su propia lógica interna, y si es posible decirlo, su peculiar "racionalidad", que a primera vista puede parecer un "simple disparate" ("barer Unsinn") 11. Restituyendo, pues, esta lógica propia, Rogge da cuenta de un sistema que tiene una sorprendente coherencia.

El fundamento hay que buscarlo en la "Germanische Freiheit", esa absoluta libertad primitiva que gobernaba la vida de los germanos, y que permite explicar muchas conductas; explica, por ejemplo, el derecho del germano a lavar el honor o vengar el daño sufrido en sus bienes o en su persona, emprendiendo junto a sus parientes y amigos una venganza contra el autor del crimen, el "derecho a la faida o venganza" ("Fehderecht") ${ }^{12}$. De su parte, el ofensor podía rechazar cualquier reparación y provocar la faida o venganza. Ninguna autoridad osaría conculcar

${ }^{9}$ EICHHORn, Karl Friedrich, Deutsche Staats- und Rechtsgeschichte (Göttigen, 18425-1844), 4 vols., pp. $422-35$.

${ }^{10}$ RogGe, Karl August, Über das Gerichtswessen der Germanen. Ein Germanistischer Versuch (Halle, 1820). Sobre este punto KroesCHell, Karl, Germania in der deutschen Rechts- und Verfassungsgeschichte, reeditado en Studien zum frühen und mittelalterlichen Recht (Berlin, 1995), pp. 89-110 (p. 99); NEHLSEN VON STRYK, Karin, Zum “Justizbegriff” der rechtshistorischen Germanistik, en Jus commune, 17 (Frankfurt a. M., 1990), pp. 189-222 (p. 194).

11 "In allen diesen scheint der baare Unsinn am Tage zu liegen": p. v.

12 "Im Zorne über die erlittene Beleidigung, über sein mit Blutt beflecktes Haus, brach der Germane auf, um Rache zu suchen an dem, den er als Thäter kannte oder mit Gewissheit vermuthete": ibíd., p. 143. A estos asuntos Rogge dedica el primer capítulo: "Germanische Freiheit", con un sub-capítulo: "Fehderecht". 
a cualquier hombre libre este derecho considerado imprescriptible, porque su palabra no podía ser puesta en duda o abiertamente falsificada por testigos u otros medios de prueba. Por tal razón, es un error considerar esta contienda simplemente como la confrontación de la palabra de una parte frente a la palabra de la otra. En las tradiciones germánicas, la palabra de un hombre libre representaba toda su propia dignidad y la de su familia. Precisamente, porque el procedimiento estaba fundado en la palabra, acompañado de su propio juramento y el de sus amigos que le avalaban (conjuradores), la "Glaubwürdigkeit", la credibilidad de un hombre y su familia se hallaba en juego con la reparación.

La sospecha de que un sistema así podría haber conducido al caos, ciertamente salta de inmediato. Pero ese riesgo se minimizaba debido al dominio solemne que ejercía la "Sitte", esto es, la costumbre, y más ampliamente la moral social rigurosa, digamos, el "imperio de las buenas costumbres" ("Herrschaft der Sitte"). Los excesos de injusticias que podrían producirse en un sistema penal así, sin autoridad superior y sin el imperio de la ley, los contenían las costumbres venerables de la comunidad. Por eso, no parece posible hablar de un orden jurídico medieval (o germánico), por cuanto no es la ley la que impera. La paz y la justicia reposaban, entonces, en la alta estima que tenía la moral social en el carácter germánico.

Desde luego, cabría pensar -dice Rogge- que, ateniéndose estrictamente al sentido de las palabras, sería algo abusivo hablar de "derecho" a la venganza, ya que no existe verdaderamente derecho sino cuando éste está garantizado por una autoridad superior. Sin embargo, la existencia de una tal autoridad entraba en contradicción con aquella libertad absoluta del germano. Entonces, en estricto sentido, el derecho a la faida era el poder de recurrir a la violencia, privilegio monopolizado en manos de los hombres libres, cuyo campo de aplicación estuvo limitado, al menos, a los asuntos criminales, ya que lo "civil" era competencia del aparato judicial.

A este derecho a la venganza se le correspondía un sustituto, "wergeld", que forma parte de un sistema de composiciones ("Compositionenrecht"), que estaba limitado igualmente al ámbito criminal. Consistía en la posibilidad que se le ofrecía a las partes, si así lo juzgaban, de renunciar a la faida. Una causalidad estructural entre los dos sistemas, el de la venganza y el de la composición, hace que se correspondan entre sí. Pero el ejercicio ilimitado del derecho a la faida, era simplemente atemperado por el sistema de composiciones, pero no restringido ${ }^{13}$.

Papel no menos importante cumplía la comunidad en el sistema jurídico germánico. Contemporizaba procurando favorecer la reconciliación entre el culpable y la víctima. Lejos de permanecer indiferente al surgimiento o irrupción de las venganzas y el reguero de violencias, pero también sin poner en duda el ejercicio ilimitado del derecho de venganza por parte de un hombre libre, ponía en práctica ciertos procedimientos para alcanzar la paz ${ }^{14}$.

Las relaciones entre el poder público ("Volksgewalt") y la libertad de los in-

${ }^{13}$ Los sub-capítulos $2^{\circ}$ y $3^{\circ}$ están dedicados a esta causalidad estructural donde estudia el wergeld y compara las faidas: "Wergeld. Vergleichung des Fehdes und Compositionenrecht", pp. 5-18.

${ }^{14}$ Capítulo 2o: "Genossenschaften und Frieden der Germanen”. En el siguiente, Rogge 
dividuos es un problema difícil, ya que ¿cómo puede conciliarse la existencia del derecho y el mantenimiento de la paz, que presupone una autoridad superior, con la libertad individual de los germanos? Rogge dice que el ejercicio del derecho de venganza concernía solamente a las agresiones físicas.

Al parecer, existía un "cuadro legal” que todo ofensor debía respetar antes de recurrir a la venganza: primero, todo ofensor tenía la obligación de comparecer ante el tribunal si era citado. Si no lo hacía, no podía ser aprehendido puesto que sería contrario a su libertad. Igualmente, no presentarse al tribunal lo excluía de la comunidad de hombres libres ("Volksgenossenschaft") y ello le privaba de la ayuda que todos los miembros de dicha comunidad debían brindar a aquellos que eran atacados. De este modo, quedaba abandonado a la venganza de su adversario, o bien podía huir fuera del país, con lo cual se aplicaba a sí mismo un castigo. Segundo, una vez delante del tribunal, el ofensor debía declarar si estaba dispuesto a pagar la composición ("Wergeld"), o se preparaba para repeler la venganza. Disponía, pues, al menos teóricamente, de ambas posibilidades. Tercero, si optaba por pagar la composición, los jueces debían fijar el monto y podían secuestrar sus bienes para asegurar su pago.

Esta comparecencia ante el tribunal constituía la única restricción que los germanos tenían en su libertad. Los procedimientos de pacificación y de reparación ("Sühnversuche") que iniciaba el tribunal podían ser contestados por alguna de las partes expresando su disconformidad. Sin embargo, habida cuenta de que los germanos tenían un alto concepto de la moral, en estricto sentido, eran obligatorios. La fuerte presión que generaban los asistentes al procedimiento -todos parientes y amigos-, impelían al ofensor a comprometerse con la vía de la composición aceptando reparar el daño causado. Se trata de un importante rol pacificador que tenía la comunidad, al que se añadía una suerte de garantía universal a través de la cual la misma comunidad le garantizaba a todo miembro que había sido víctima de una ofensa, el pago de la indemnización o wergeld. Era un poderoso medio para convencer a las víctimas de aceptar la mediación de la paz o composición ("Friedensvermittlung"), lo cual, en la mayoría de los casos, se lograba. Ciertamente, porque una mediación de paz no tiene fuerza sin una garantía ${ }^{15}$.

Concebido así el sistema jurídico germánico, Rogge afirma que entre los germanos el derecho penal era extraño ("Nichts war den Germanen so fremd, als ein Strafrecht"), pero en cambio el fundamento del derecho criminal de los germanos era, en verdad, "pura doctrina de reconciliación" ("reine Versöhnungstheorie") que no puede relacionarse, en modo alguno, con la ley del talión. La comunidad no tenía el derecho de intervenir con el objetivo de castigar, sino reparar el daño causado, buscando siempre en ello reconciliar a las partes en conflicto y permitir el restablecimiento de la paz. Por tal razón, los factores psicológicos como la intencionalidad o la no-intencionalidad de la falta, el sistema penal germánico

explica el funcionamiento de las instituciones judiciales germanas: "Germanische Gerichtsverfassung”.

15 “Ohne eine Guarantie ist jede Friedensvermittlung ohne Kraft”: ibíd., p. 26. 
no los tomaba en cuenta. Simplemente, había una falta cometida, luego había de ser reparada para que regresara la paz $^{16}$.

Una sesión del tribunal era una suerte de faida pacífica donde cada una de las partes afirmaba su derecho mostrando su fuerza, entendiendo que se trataba de un sistema donde la presión social que lograba ejercer la comunidad circundante era de tal manera importante, que un culpable tenía muy pocas posibilidades de poder mostrar su fuerza y por ello justificarse; la sociedad le obligaba a ceder.

Al preguntarse Rogge acerca de si los germanos tenían un sistema de pruebas ("kannten die Germanen ein Beweisverfahren?"), entra en uno de sus argumentos de fondo. Con ello pretende demostrar que los germanos carecían de un sistema de pruebas a la manera como actualmente conocemos. Lo aborda con ímpetu cuando estudia el funcionamiento de los tribunales y el rol de los conjuradores. Estos no son testigos a la manera como los entendemos hoy, ya que solían ser parientes o amigos del acusado, con lo cual vemos que no se cumplía ningún requisito de un testigo imparcial. De hecho, estas eran las mismas personas que participaban en la faida como protagonistas principales, o que contribuían al pago del "Wergeld" de la víctima. Generalmente, el papel que les tocaba en los procesos era el mismo, esto es, permitirle a la parte que asistían mostrar la fuerza y afirmar su derecho, sin que fuera necesario acudir a la faida.

La tesis de Rogge sobre la existencia de un orden jurídico medieval sui generis, sin un orden judicial y sin derecho penal pero sustentado en unos procedimientos de pacificación, habría de provocar reacciones tanto en Alemania como en Francia. Toda la historia del derecho alemán medieval, abordada por historiadores del derecho o por historiadores propiamente tales, será dependiente de Rogge en sus puntos de partida, sea para construir desde él mismo, como también y especialmente para oponérsele. Adherirse a éste, implicaba renunciar a la idea de que los germanos hayan podido tener un auténtico derecho penal. En efecto, el derecho a la venganza, entendido como un derecho, o más aun, una "libertad" reconocida a cada uno de hacer respetar él mismo su derecho y honor -la exaltación misma de la libertad germánica original-, no podía ser compatible ni con la construcción de un Estado ni con la existencia de un derecho penal organizado. Había que mostrar que el ejercicio de este derecho a la venganza no procedía de esa libertad original de los germanos, esto es, de una libertad anterior a la instalación de un orden estatal o jurídico, o digamos, de un estado natural bárbaro. Por el contrario, era preciso demostrar que el derecho a la faida no era una explosión de irracionalidad en estado salvaje, sino un derecho cuya legitimidad emanaba del mismo "orden estatal" impuesto por la comunidad ("Volksgenossenschaft") a todos sus miembros, no pudiendo ejercerse sino en el momento y lugar que ella

16 “[...] eine reine Versöhnungstheorie; sehr verschieden von der Vergeltungslehre: nur Unfreie konnten eine Strafe, als die von höherer Hand geübte Vergeltung von ihren Herrn empfangen. Es lässt sich daher von selbst erwarten, dass in dem germanischen Compositionsrechte ganz andere Ideen die leitenden waren, als in einem bürgerlichen Strafrechte. Psychologische Rücksichten waren jedem durchhaus fremd. Wer dem Germanen zu nahe getreten war, musste ihn versöhnen auf die gesetzliche Weise, oder seine Rache empfinden, gleichviel ob er dafür gekonnt hatte oder nicht": pp. 29-30. 
establecía. Por último, era justo aclarar que esta costumbre, andando el tiempo, había ido poco a poco siendo atemperada, tarea que habría de emprenderla Wilhelm Eduard Wilda.

\section{Wilhelm Eduard Wilda.}

Wilda no escaparía a la escisión producida en Alemania en la escuela histórica del derecho entre germanistas y romanistas, la cual, hemos visto, influía en la apreciación del derecho medieval. Siguiendo a Friedrich von Savigny y el principio denominado "Spezialistendogma”, sostenía que los especialistas del derecho, los glosadores, habían sido los mejores intérpretes del derecho medieval, entendido éste como la expresión del espíritu de un pueblo. Si se decía que el derecho positivo existe en el seno de todo pueblo independientemente que se exprese o no mediante una ley, ha de entenderse que se trataba, pues, de un derecho inmanente que había que descubrir en ese "Volksgeist". Por tal razón, negaban al pueblo toda capacidad para crear en materia de derecho ("rechtsbildende Kraft"), aludiendo al proyecto de crear un derecho civil para Alemania; pero, a partir de esta coyuntura decimonónica, se deducía que si en la Edad Media el imperio de la ley positiva -escrita- se había debilitado debido a la irrupción del derecho costumbrista germano, ello no permitía concluir la ausencia de ley y de un sistema legal medieval.

Los germanistas, en cambio, defendían la idea de un desarrollo orgánico del derecho continuamente readaptado a la organización de la sociedad y sus necesidades. En esta línea, Wilda se propone escribir una historia del derecho penal alemán desde sus orígenes que tituló Das Strafrecht der Germanen que se publicó en $1842^{17}$, con la intención de probar la existencia de un derecho penal germánico independiente del derecho penal romano. Aun cuando los tomos que prometía Wilda no llegaron a conocer la luz pública, dice Jean-Marie Moeglin, este libro debe considerarse como pionero de la tradición jurídica alemana de la historia del derecho penal medieval ${ }^{18}$.

De acuerdo a las enseñanzas de la escuela histórica del derecho, aquél debía ser considerado como una fuente siempre viva del derecho penal contemporáneo. En las fuentes, Wilda quería reconocer un panorama de sus precisos contenidos, en los que debía ser reconocida la conciencia popular germánica, de la cual provenía toda la organización del derecho, para separarla de lo perteneciente a la particular formación y desarrollo de los diferentes pueblos germánicos ${ }^{19}$. Se trataba, pues, de cómo se llega a comprender la homogeneidad dentro de la diversidad ("Wie man zur Erkenntniss des Einheitlichen in dem Mannigfaltigen gelangt ist [...]”).

\footnotetext{
${ }^{17}$ WILDA, Wilhelm Eduard, Das Strafrecht der Germanen (Halle, 1842; reimpresión Aalen, 1960).

${ }^{18}$ Moeglin, Le droit de vengeance, cit. (n. 3), p. 122.

19 "Es ist daher eine genaue Kenntniss jener Quellen, eine Vergegenwärtigung ihres Inhalts erforderlich, um das, was aus dem germanischen Volksbewusstsein hervorgegangen, was als allgemein germanische Rechtseinrichtung anzuerkennen ist, zu erfassen und von dem, was der particularen Entwicklung und Gestaltung angehört, auszuscheiden”: p. xiii; véase también la p. xii.
} 
De acuerdo a la manera que se haya atestiguada entre los germanos, Wilda juzga la venganza como un sentimiento noble, que testimonia el sentimiento subjetivo de la justicia y del derecho. Por cierto, a priori no cabría estimarlo demasiado, si entendemos que no es compatible con la existencia de una organización estatal, aunque sea embrionaria. No es fácil integrar la venganza como una institución del derecho ("Rechtsinstitut"), en un derecho penal germánico si se trata precisamente de restituir sus contornos. Wilda propone genialmente un concepto que habría de tener una enorme importancia en la tradición jurídica alemana hasta una época muy reciente: "Friedlosigkeit", que a falta de una traducción histórica mejor, nos adherimos a la propuesta de Jean-Marie Moeglin, como "supresión fuera de la paz"20.

Dada la importancia de este concepto, del que pende casi toda la argumentación, Wilda la define así: "Del restablecimiento de la Friedlosigkeit a su verdadero lugar y a su verdadera importancia, depende en buena medida una concepción exacta de casi todo el derecho penal de los germanos. La Friedlosigkeit es, según su principio fundamental, una exclusión de la comunidad de la paz y del derecho, provocado, por así decirlo, por el hecho de haberse hecho culpable de una violación del respeto a que está obligado. Ella no excluía solamente a aquel que había roto la protección jurídica, y no solamente lo ponía en la situación de un no-miembro, de un extranjero, lo convertía en enemigo de su pueblo y de su rey" ${ }^{21}$.

Dentro de los límites fijados por las leyes, el ejercicio de la venganza era legítimo y legal puesto que se castigaba a un culpable cuyo acto le había puesto a sí mismo, ipso facto, le había situado legalmente "friedlos", esto es, fuera de la paz común; en esas circunstancias, podía ser legalmente perseguido y castigado. La venganza no debe ser considerada como un sustituto ante la ausencia de pena, sino que era la pena misma. Asumido el estado primitivo del derecho germánico, ello aseguraba un vasto campo al ejercicio legal de la venganza. Esta "Friedlosigkeit" que permitía el ejercicio de la venganza, solía ser decidido por el tribunal, pero también podía ser aplicada de oficio cuando el malhechor estaba evidentemente identificado.

En contra de Rogge que veía en la faida un ejercicio desenfrenado y sin control, el argumento de Wilda asegura que los germanos conocieron un orden judicial y un derecho, y que habiendo aceptado durante mucho tiempo el reconocimiento del derecho a la venganza, sin embargo le asignaron un status legal. No obstante,

20 "Retranchement hors de la paix": Moeglin, Le droit de vengeance, cit. (n. 3), p. 123. WILDA, Das Strafrecht cit. (n. 17), cap. 40 se titula: "Vom Frieden, den Friedensbrüchen und der Friedlosgkeit" cuya letra C: "Von der Friedlosigkeit", está dedicada íntegramente a este tema: 1.- Begriff derselben, 2.- Folgen der eigentlichen Friedlosigkeit, 3.- Modificationen der strengen Friedlosigkeit, 4.- Friedlosigkeit vor dem Urtheil (pp. 221-312).

21 "Von der Wiedereinsetzung der Friedlosigkeit in deren wahren Stelle und Bedeutung hängt grossentheils die richtige Auffassung fast des ganzen Strafrechts der Germanen ab. Die Friedlosigkeit est dem Grundgedanken nach eine durch Verschuldung, gleichsam durch einen Treubruch begründete Ausschliessung aus der Friedens- und Rechtsgemeinschaft, welche dem davon Betroffenen nicht nur den Rechtsschutz entzog und in die Lage eines Ungenossen, eines völlig Fremden versetzte, sondern ihn als Feind seines Volkes und des Königs bezeichnete": WiLDA, Das Strafrecht, cit. (n. 17), p. 278. 
este ejercicio de la venganza sobre los criminales aprehendidos en el hecho, la tendencia fue limitarlo cada vez más en el marco de esta "Friedlosigkeit" instaurada de oficio. Ésta, sin duda, constituía una pena, pero una pena cuya puesta en marcha, evidentemente, ponía en peligro el buen orden de la sociedad. Ante tamaño riesgo, los germanos disponían de las compensaciones, "Bussen", las cuales otorgaban cierta satisfacción al germano mancillado en su honor ${ }^{22}$. No se trataba, como sostenía Rogge, de un medio para evitar el desencadenamiento de la guerra, sino un castigo del crimen fijado por el derecho. Aun más, no le estaba dado al ofensor decidir si aceptaba la compensación o se entregaba a la faida. La institución del "Wergeld" había creado una tabla para estas compensaciones, que el tercer estadio evolutivo del derecho germánico, situado en la época carolingia, fue modificando para dar lugar a las penas aflictivas impuestas a los criminales por la fuerza pública, es decir, que la venganza quedaba ahora en manos del "Estado".

Wilda intenta reconstituir la evolución lógica del "Strafrecht" en diversos estadios: en los orígenes, el fundamento legal del ejercicio de la venganza, y de todo el derecho penal originario era la "Friedlosigkeit". Siendo un instrumento peligroso para la estabilidad de la sociedad, ella fue dando paso a un nuevo estadio que ve aparecer las compensaciones determinadas por unas tarifas. Estas cedieron su lugar a un derecho represivo que contemplaba penas corporales. Solamente en este tercer estadio se podía afirmar que venganza privada y castigo se habían definitivamente separado, aun cuando en el primer estadio, la venganza no podía llevarse a cabo legítimamente sino en el marco legal dado por la "Friedlosigkeit".

Es justo decir que Rogge había introducido dicha noción sin emplear este concepto cuando explicaba la labor pacificadora de las instituciones judiciales. Había postulado la inexistencia de una fuerza estatal coercitiva que no castigaba al violador de la paz que no comparecía ante el tribunal, sino que aquél mismo de desterraba después de haber quebrantado las venerables costumbres. Esta carencia de fuerza pública era el punto débil de Rogge, y en este vacío se introdujo Wilda planteando que la "Friedlosigkeit" no debía concebirse como un sustituto de la fuerza coercitiva del Estado, sino más bien era ella misma.

Como una institución legal, dice el autor, el derecho de venganza había sido compatible con el orden jurídico medieval. Sólo era mínimamente limitado y no debe confundirse con el derecho a la faida-el "Fehderecht"-, es decir, entenderlo como el derecho a emprender una acción contra los vecinos por la razón que sea. Wilda era de opinión que este derecho jamás tuvo existencia legal, aun cuando en las fuentes se aprecien confusiones. Era preciso, indicaba, comprender que cuando las fuentes otorgan el derecho a la víctima de proceder con la faida contra su ofensor, se tratada de un derecho a la venganza que no estaba fuera de la ley, y que era ejercido contra todo individuo en estado de "Friedlosigkeit", esto es, que había sido expulsado debido al crimen cometido. La venganza, pues, no estaba fuera del Estado.

Sin embargo, resulta sorprendente que la noción de "Friedlosigkeit" introducido por Wilda, al no encontrar su comprobación en las fuentes documentales, no

\footnotetext{
${ }^{22}$ Capítulo V: “Von den Bussen”, pp. 314-481.
} 
sea más que una extraordinaria construcción teórica sin existencia real, digamos, una entelequia. No obstante, este concepto debe ser considerado una genialidad, pues le permitía a Wilda hacer compatible lo que parecía no serlo, es decir, la realidad de un orden jurídico - derecho penal- con el ejercicio de la venganza. Si ello permitía a la historiografía alemana interesarse vivamente por estas formas peculiares de entender la justicia -justicia germánica-, en cambio, a los historiadores franceses, que veían solamente barbarie y anarquía en todas estas conductas incompatibles con la presencia de un derecho, no se interesaron por hacer de este tema un objeto de estudio.

\section{Georg Waitz.}

Habiendo estudiado derecho e historia, en 1844, contando apenas 31 años, publicó en Kiel la monumental Deutsche Verfassungsgeschichte en ocho tomos, obra que habría de tener una poderosa y perdurable influencia, lo cual explica sus varias reediciones ${ }^{23}$. El primer volumen está dedicado a la organización de los pueblos germánicos.

Ninguna sociedad, decía, puede ser comprendida por los historiadores, sino cuando aquella alcanza un mínimo de orden jurídico que se impone a todos sus miembros, lo cual la constituye en una comunidad. Por eso Waitz tenía la convicción de que el conocimiento del derecho particular de cualquier sociedad, era la mejor herramienta para alcanzar a entender su propia historia.

Siguiendo el argumento, Waitz sostenía que los germanos habían entrado en la historia solamente en el momento que lograron constituirse en una comunidad de propietarios libres, según la descripción de Tácito. Había, pues, que refutar la tesis de Rogge sobre la inexistencia de un orden jurídico superior al individuo en la época germánica, y para tal cometido se propuso integrar la reflexión de Wilda sobre el derecho penal de los germanos dentro de un cuadro de análisis más amplio, el de la organización socio-política, la "Verfassung".

Oponiéndose al planteamiento de Rogge, su crítica es fuerte: "Para nosotros que pertenecemos a una generación más tardía, nos parece casi incomprensible que el libro de Rogge haya podido adquirir tal fama, la más grande en palabras de Grimm en una nota en el prefacio de sus Antiquités allemandes du droit. Después de lo que había sido escrito por Eichhorn y Savigny no debía parecer nada extraordinario, sino rectificar en detalle tal o cual punto, o precisar un poco más las cosas. Desde un punto de vista general, la exposición [de Rogge] ha dado lugar a tantos errores, sus concepciones son tan equivocadas que es apenas necesario desear todavía rectificarlas. Allí donde era realmente necesario, Wilda lo hizo de manera suficientemente profunda y detallada" 24 .

${ }^{23}$ WaITZ, Georg, Deutsche Verfassungsgeschichte (Kiel 1844-1878; 2a edición 1865-1870; $3^{\mathrm{a}}$ edición 1880-1896; 4a edición 1953). Sobre el autor la noticia de A. ERLER en Handwörterbuch zur deutschen Rechtsgeschichte, V, col. 1103-1104.

24 "Uns Nachgebornen erscheint es doch fast unbegreiflich, wie Rogge's Buch so grossen Ruhm erworben hat, den grössten durch Grimm's Wort in der Vorrede zu den R.A. p. VII $\mathrm{n}^{*}$. Nachdem Eichhorn und Savigny geschrieben, war es doch nicht so ausserordentliches, imeinzelnen manches genauer anzuführen und schärfer zu bestimmen. Im allgemeinen hat die 
En este sentido, apartándose sensiblemente de Karl August Rogge cuando se rehúsa a idealizar a los germanos descritos por Tácito, Waitz centra su atención en entender y también perfeccionar el planteamiento teórico de Wilhelm Eduard Wilda sobre la "Friedlosigkeit". Desde luego, su reivindicación de los germanos no llega a considerarlos primitivos como sostenía Guizot. El pasaje es notable: "habitantes germanos y sobre todo extranjeros no se apartan de la afirmación de Tácito que cada alemán fue en tiempos un salvaje y que ha habitado en otros lugares del mundo de manera no muy diferente a la forma de vida y al estado tradicional y desarrollo intelectual. No puedo decidir refutar detalladamente este punto de vista. Quien no se puede convencer de lo contrario, no hay historia para él. Tampoco se puede decir, de acuerdo a la opinión de algunos, que los germanos son un pueblo mejor, más perfecto y puro que cualquier otro en el curso de la historia" 25 .

$\mathrm{Si}$, en efecto, es por su libertad lo que define fundamentalmente a un germano, ésta es más bien la libertad de gozar de los derechos posibles, los cuales se generaban únicamente por su participación en una comunidad política de hombres libres, incluso antes de la existencia del Estado. Sus raíces no están en la familia, sino en la comunidad. El Estado se genera si las comunidades de hombres libres -el pueblo mismo-, se unen políticamente, y de las relaciones que se establecen, se constituye el derecho. Fuera de esta "Volksgenossenschaft", no existía libertad posible ${ }^{26}$. Y dado que la paz se identificaba con el estado de derecho ("der Zustand des Rechts"), cualquier atentado a la paz lo era también al derecho y viceversa. La punición por la ruptura de la paz era la "Friedlosigkeit", la solemne expulsión de la sociedad, la privación de ella al violador, ya que no era digno de participar de la paz. Aquí aparece descrita la equivalencia simple de la "Friedlosigkeit" con el crimen, que corresponde a un estadio evolutivo muy antiguo de la sociedad germánica, anterior al descrito por Tácito. Ya en contacto con los romanos, los germanos diferenciaban los crímenes y aplicaban penas específicas para cada uno

Darstellung gewis zu grossen Irrthümern Anlass gegeben, die Auffassung ist hier oft so wunderlich, dass man es kaum noch aussführlich widerlegen mag. Wo es Noth thut, hat es Wilda gelehrt und gründlich und aussführlich genug gethan": WaITZ, Deutsche Verfassungsgeschichte, cit. (n. 23) (1a edición Kiel 1844), p. 184.

25 "Auch Einheimische, besonders aber Fremde lassen nicht ab von der Behauptung, jene Deutsche die Tacitus kannte seien Wilde gewesen wie sie heute und seit Menschengedenken in den andern Erdteilen wohnen, nicht wesentlich verschieden weder in der Art des Lebens und allen äussern Zuständen noch an sittlicher Kraft und geistigem Vermögen. Ich kann mich entschliessen diese Ansicht ausführlich zu widerlegen. Wer sich nicht anders überreden kann, für den giebt es keine Geschichte. Ebenso wenig aber bin ich gemeint, denjenigen beizustimmen welche in den Germane nein Volk erkennen, das besser, volkkommener, reiner gewesen als irgend ein anderes der Geschichte": ibíd., p. 6.

26 "Ist die wahre Freiheit gegeben mit der Bildung der Gemeinde, so tritt auch mit dieser sofort das Rechts als solches ins Leben. Es giebt kein Recht ohne den Begriff des Staats, vor den Anfängen desselben; aber es entsteht so wie sich die einzelnen on solcher Gemeinschaft fülhen; nicht in der Familie hat es seine Wurzeln, sondern in der Gemeinde; - denn so nenne ich jene Anfänge des staatlichen Lebens; der Staat selbst entsteht wenn die einzelnen Gemeinden des Volkes sich zur politischen Einheit verbinden. Und das Recht ist dann der Mittelpunkt aller Verhältnisse": ibíd., p. 184. 
de ellos. En un momento histórico así, se instauró la práctica de las composiciones ("Bussen”).

El esfuerzo de Waitz busca probar la legalidad de las prácticas judiciales aparentemente no racionales como la venganza. El régimen de composiciones representa un impedimento de la faida a través de las indemnizaciones ("Schadenersatz") específicas. Pero éstas no deben concebirse solamente como resarcimientos personales y un castigo al ofensor, sino muy especialmente una satisfacción a la comunidad política. Es la razón por la cual el derecho a la venganza no fue abolido; y siendo legal, no entraba en contradicción con las normas dadas por la comunidad. Desde luego, cualquier extralimitación podía darse, esto es, el desarrollo de una venganza acompañado de la familia, pero eran ilegales, afirma Waitz.

\section{Karl Von Amira.}

Los historiadores del derecho entraron al ruedo. Karl von Amira reflexionó sobre la "Friedlosigkeit" y sus consecuencias, casi simultáneamente a Heinrich Brunner, a quien examinaremos enseguida. Amira sostiene que la "Friedlosigkeit" habría sufrido un proceso evolutivo de disociación: en primer lugar, se convertiría en un sistema de puniciones sagradas cuyo objetivo era la purificación ritual y religiosa de la comunidad manchada por un crimen, y expuesta a la venganza de los dioses. Por eso los crímenes considerados "irremisibles" contemplaban el sacrificio del culpable a los dioses. Por otro lado, estaba el castigo a los malhechores de crímenes estimados "normales". Todo ello no habría sido un producto de la "Friedlosigkeit" original, sino más bien una evolución histórica en que la sociedad germánica se adaptó a las nuevas circunstancias dadas por el tránsito del mundo antiguo al medieval: coexistieron en el antiguo derecho penal germánico un sistema sacral, que se ocupaba de los hechos injuriosos que violaban la paz, y otro profano, que cubría otras faltas comunes. En su famosa lección inaugural (“Eintrittsvorlesung”) de 1875, señaló: “yo mismo hace 46 años esquematicé los lineamientos del proceso penal de los germanos, donde coexistían dos sistemas, uno sagrado y otro profano. El sagrado se refería a los quiebres de la paz, que se representaban como hecho vergonzosos; sobre ellos (salvo la supresión de la paz) estaba el castigo público, es decir, la pena de muerte con propósito de sacrificio. El sistema profano se refería a todos los otros quiebres de la paz. A ellos seguían otras supresiones de la paz" ${ }^{27}$. Amira persistió en esta opinión.

27 "Ich selbst habe vor 46 jahren die Grundlinien des altgermanischen Strafrechts dahin skizziert, dass nebeneinander zwei Systeme bestanden, ein sakrales und ein profanes. Das sakrale bezog sich auf diejenigen Friedensbrüche, die sich als schimpfliche Taten (Neidingswerke) darstellten; auf sie war (ausser der Friedlosigkeit) öffentliche Strafe, nämlich Todesstrafe mit Opferzweck gesetzt. Das profane System betraf alle übrigen oder die gemeinen Friedensbrüche; ihnen folgte schlichte Friedlosigkeit. An dieser ansicht habe ich auch später festgehalten. [...]”: Aмira, Karl von, Die Germanischen Todesstrafen. Untersuchungen zur Rechts- und Religionsgeschichte (München, Abhandlungen der Bayerischen Akademie der Wissenschaften- Philosophischphilologiche und historische Klasse, XXXI, 3, 1922), p. 4. 


\section{Heinrich Brunner.}

Desde Berlín, Heinrich Brunner se convertiría en una suerte de "papa" de la historia del derecho en Alemania. Se opondrían a la escuela histórica del derecho, todavía representada por Otto von Gierke, con el fin de cultivar la historia del derecho en sí misma.

Brunner y su discípulo Claudius von Schwering se propusieron dar forma jurídica a los planteamientos sustantivos de Wilda, conceptualizando unas bases del derecho penal antiguo. Consistía en construir un sistema jurídico perfectamente coherente, cuyos principios se deducían de manera lógica de las fuentes documentales ${ }^{28}$.

El concepto de "Friedlosigkeit" no es exactamente el mismo que se encuentra en Wilda y Waitz. Éstos lo habían usado con el fin de comprender la existencia de un derecho penal medieval, y más todavía un orden jurídico y judicial germánico, coexistiendo con el derecho a la venganza. Ahora se convertía en la piedra angular desde donde se desarrollaba todo el sistema penal medieval y moderno. Brunner creaba el concepto de "Abspaltung" ("Secesión”) con el cual daba a entender un proceso de disociación de la "Friedlosigkeit" original que afectaba a todo infractor. Desde aquí surgían todas las sanciones del derecho penal antiguo y moderno ${ }^{29}$.

Según Brunner, la "Friedlosigkeit" presentó una doble imagen:

La "Friedlosigkeit absoluta": ésta afectaba a los autores de un hecho punible perturbando al conjunto de la comunidad en sus fundamentos más sagrados, y condenando a los culpables al destierro ("Acht"), apartados de toda la comunidad o sociedad. Como había estudiado Amira, la Friedlosigkeit habría evolucionado hacia un sistema de castigos terribles y sagrados, cuyo objetivo era dar satisfacción a los dioses ofendidos y evitar que su furia se lanzara contra los hombres.

La "Friedlosigkeit relativa": esta concernía todo homicidio que el miembro de un clan familiar había cometido contra el miembro de otro clan, que generaba el enfrentamiento entre "Sippen". Era una Friedlosigkeit relativa ya que el autor de un crimen no quedaba fuera de la comunidad. En verdad, lo volvía "Friedlos", es decir, lo ponía fuera del respeto de los miembros de la "Sippe" a la que pertenecía la víctima, la cual tomaría la venganza para castigar el crimen. Aun cuando sobre el ofensor, y solamente a él, recaía ipso facto la "Friedlosigkeit", esto es, la indefensión del derecho, con todo quedaba expuesto al riesgo de que el clan familiar hiciera uso de su derecho a la faida no solamente sobre el mismo criminal sino contra algún miembro de su clan.

Wilda primero y después Waitz habían afirmado la legalidad del derecho a la venganza, Brunner estudió ampliamente los clanes familiares y la wergeld a partir de los códigos de los "reinos bajo-alemanes", negándose a admitir la existencia legal a la faid $a^{30}$. Más que un derecho propiamente tal, era un juego normal de solidaridades familiares que inevitablemente desembocaba en "vendetta", mientras

\footnotetext{
${ }^{28}$ Brunner, Heinrich, Deutsche Rechtsgeschichte (Leipzig, 1887).

${ }^{29}$ Brunner, Heinrich, Die Abspaltungen der Friedlosigkeit, en Zetschrift der Savigny-Stiftung für Rechtsgeschichte, germ. Abt., 11 (1890), pp. 62-100.

${ }^{30}$ Brunner, Heinrich, Sippe und Wergeld nach niederdeutschen Reichen, en Zeitschrift der Savigny-Stiftung für Rechtsgeschichte, germ. Abt., 3 (1882), pp. 1-101.
} 
el resto de la comunidad integrada por las otras Sippen asistían a esta guerra, dice Brunner, con los brazos cruzados" ("mit verschrankten Armen”), observando sin intervenir: "las fechorías por las que podía surgir una faida legítima, no tienen ninguna consecuencia jurídica sobre la posición del culpable frente a su grupo de parientes; no suprimen su pertenecía a su clan familiar. Si éste no lo excluye voluntariamente, se considera que debe proteger al integrante que ha sido atacado. Habida cuenta de la existencia de un vivo sentimiento de estrecha solidaridad entre los miembros de un clan, hace que la preocupación por un individuo, sea la preocupación por todo el grupo. La faida de los antiguos germanos es una guerra entre parentelas, una guerra entre dos grupos de parientes enemigos, de cuyo desarrollo el resto del pueblo asistía con los brazos cruzados" ${ }^{31}$.

El surgimiento del sistema de composiciones constituía un paso histórico que superaba la venganza, y ello habría ocurrido en “época germánica”, es decir, con anterioridad a la fragmentación popular de los germanos en el momento de acceder a las tierras del Imperio ${ }^{32}$.

\section{Franz Beyerle.}

Este autor publica en 1915 una obra que puso en cuestionamiento las teorías de la antigua escuela que se esforzaba por conciliar la existencia del derecho a la venganza con un estado de derecho que garantizara la paz. El texto se titula Das Entwicklungsproblem im germanischen Rechtsgang ${ }^{33}$.

Las teorías planteaban que las partes en conflicto debían oscilar entre el libre ejercicio de la venganza o el recurso a los procedimientos de composición y de solución de conflictos a cargo de los tribunales. En esas condiciones, ¿Es posible la existencia de un Estado que garantice la paz? Beyerle mostraba que la invención de la "Friedlosigkeit" de la teoría clásica, había sido una respuesta a la aporía permitiendo conciliar la existencia de la faida y la existencia del estado que asegura la paz. Al referirse a Rogge y a su teoría, Beyerle señalaba que "su concepción de la libertad germánica le condujo a la hipótesis de que habría sido permitido, en la época de las leyes bárbaras, recurrir sea a la faida, sea a la composición por compromiso. Es aquí que Wilda cae en una contradicción; ésta iba contra la idea de una continuación del ejercicio privado de la fuerza en el marco de una comunidad estatal, es decir, contra el derecho a la venganza en el sentido de Rogge. En el lugar de la faida ponía, como reacción directa a la injusticia, la perdida de la paz, cuyo sustituto era el procedimiento de la composición". La contradicción, a su parecer, era concebir la continuación del ejercicio privado de la fuerza en el marco de una comunidad estatal ${ }^{34}$.

No era esto sino un postulado, una construcción lógica que no correspondía a la realidad de los hechos, y que simplemente se había inventado para no tener que

\footnotetext{
${ }^{31}$ Brunner, Deutsche Rechtsgeschichte cit. (n. 28), I, pp. 158-159.

${ }^{32}$ Ibíd., p. 221 ss.

${ }^{33}$ BeYERLE, Franz, Das Entwicklungsproblem im germanischen Rechtsgang, I: Sühne, Rache und Preisgabe in ihrer Beziehung zum Strafprozess der Volksrechte (Heidelberg, 1915).

${ }^{34}$ Ibíd., p. 207.
} 
renunciar a la idea de un Estado que garantizara la paz ${ }^{35}$. En consecuencia, había una antinomia radical entre la faida y el Estado, ya que éste se habría construido sobre la voluntad de hacer desaparecer la venganza. De esta voluntad original surgía toda la evolución de los procedimientos judiciales.

El estudio del derecho germánico permitía encontrar los niveles evolutivos de la pugna entre el orden jurídico del Estado en proceso de consolidarse, y las leyes más primitivas de la venganza de sangre y de la faida ${ }^{36}$. Cuando las leyes bárbaras evocaban la venganza no significaba que en verdad la autorizaran, sino más bien procuraban limitarla cuanto fuera posible hasta hacerla desaparecer. La permanencia de la faida en la época de los reinos bárbaros, y también más tarde, según Beyerle, debía ser comprendida como un arcaísmo sobreviviente de concepciones anteriores al proceso de construcción del Estado medieval.

El ejercicio de la venganza, y su consecuencia directa, la muerte, era, pues, un procedimiento cuya esencia era muy anterior al nacimiento del Estado ${ }^{37}$, aún cuando la faida haya perdurado un cierto tiempo después del nacimiento de ese Estado. El orden jurídico del Estado habría convivido con las leyes de la venganza privada antes de que aquél lograra erradicarlas

Tanto la antigua escuela como también el mismo Beyerle compartían la convicción de que las faidas existieron y están atestiguadas en las expresiones del derecho germánico. Pero separaron sus puntos de vista cuando la antigua escuela tomó la opción teórica de entender el derecho a la venganza como un recurso legal al interior del Estado; Beyerle, por el contrario, señalaba que el Estado y todas sus instituciones, durante el transcurso de un largo proceso jalonado de diferentes etapas, rechazó fuertemente la resolución de los conflictos mediante la venganza. Sin embargo, coexistieron dos formas de resolución de conflictos: en primer lugar, el ejercicio de la venganza y la resolución privada de los conflictos, heredero de un pasado anterior a la formación del Estado; y en segundo lugar, la imposición del derecho objetivo creado por el Estado y la exclusión de la faida.

La crítica a las teorías de Beyerle fueron, aunque corteses en la forma, muy duras en el fondo de parte de los historiadores del derecho, puesto que se trataba de un ataque frontal a la teoría entonces en boga. Claudius von Schwering reaccionó señalando que lo que el escritor dice significa un cambio revolucionario en las bases de la concepción más antigua del derecho penal y estatal. No podía admitir que el autor le hubiera convencido de la inexactitud de la concepción dominante ${ }^{38}$. Lo hizo también, críticamente, Otto von Gierke, cuando al comentar el libro de

${ }^{35}$ Ibíd., p. 218 ss.

36 "zwischen der sich festigenden staatlichen Rechtsordung mit den primitiveren Gesetzen von Blutrache und Fehde": BEYERLE, Das Entwicklungsproblem, cit. (n. 33), p. 465.

37 "wie die Rache überhaupt, so ist auch die handhaft erfolge [Tötung] eine Erscheinung, deren Sein über die Gerburttsstunde des Staats weit zurückreicht": BEYERLE, Das Entwicklungsproblem, cit. (n. 33), p. 466.

38 "Was der Verfasser hier ausführt, bedeutet eine Umstürzung grundlegender Auffassungen vom ältesten Strafrecht und Staatrecht... Ich kann dem Verf. Nicht zugeben, dass er mich von der Unrichtigkeit der herrschenden Auffassung überzeugt habe [...]": reseña de SCHWERING, Claudius von, en Zeitschrift der Savigny-Stiftung für Rechtsgeschichte, germ. Abt., 36 (1915), pp. 503-526. 
Beyerle expresaba que, a su modo de ver, la existencia de un derecho subjetivo no era posible sin la presencia de un orden legal objetivo y un orden de la paz: "en mi concepción, la idea de un derecho subjetivo nunca se ha acompañado de la idea de orden legal y de paz. Todo derecho surgido de una comunidad y la estatización del derecho, no es un parecer, sino que tiene una creación propia a partir del pensamiento objetivo acerca del derecho" ${ }^{39}$. Y en igual sentido se pronunció Heinrich Brunner en la reedición de su Deutsche Rechtsgeschichte de $1928^{40}$.

Las teorías de Beyerle no fructificaron en la intelectualidad de la época, al tiempo que él mismo no continuaría investigando en esta vía. Ocultas durante un tiempo, solamente se las redescubriría hace muy poco después del hundimiento de la teoría de la antigua escuela.

\section{Otto Brunner.}

La Société féodal de Marc Bloch ha sido para la historiografía medieval francesa una obra emblemática. Para la historiografía alemana, Land und Herrschaft de Otto Brunner, publicada en 1939 y traducida después al italiano y al inglés, se convirtió en un punto de referencia hasta $1980^{41}$. Bien que Brunner trata un período más bien tardío, no obstante las estructuras políticas y sociales del Archiducado de Austria a fines de la Edad Media son comparables a aquellas de la Francia de períodos anteriores. Aquí interesa su análisis de la época germánica primitiva y la Alta Edad Media.

Land und Herrschaft es una obra con una profunda coherencia. La primera parte dedicada a la faida, tiene el objetivo de mostrar la existencia de un elemento de la "Verfassung" (cuya traducción es a la vez "sociedad" y "configuración jurídico-política” o "constitución”) medieval que el pensamiento histórico clásico no supo integrar en su construcción, ocupado como estaba de encontrar en las configuraciones políticas medievales las prefiguraciones del Estado moderno del siglo XIX. Este era una suerte de figura eterna del Estado, adonde debía tender toda construcción política histórica ${ }^{42}$. Superada esta obsesión, creía Brunner posible una reconstitución de las configuraciones políticas medievales fundadas

39 "An Fehderecht und Bussschuld für die Urzeit halte ich fest. Nach meiner Auffassung ist die Vorstellung eines subjektiven Rechts niemals ohne die begleitende Vorstellung einer objektiven Rechts- oder Friedensordnung vorhanden gewesen, alles Recht aus der Gemeinschaft herausgewachsen und die Verstaatlichung des Rechts nicht, wie es bei Ihnen den Anschein hat, erst die eigentliche Schöpfung des objektiven Rechtsgedankens": comentario de Otto von Gierke al libro de Beyerle, en carta de 11 de junio de 1915, citada por Hans THIEME, Nachruf Beyerle, en Zeitschrift der Savigny-Stiftung für Rechtsgeschichte, germ. Abt., 96 (1979), p. xxviii.

${ }^{40}$ BRunner, Heinrich Deutsche Rechtsgeschichte (München - Leipzig, 1928), p. 692.

${ }^{41}$ BRUnNER, Otto, Land und Herrschaft. Grundfragen der territorialen Verfassungsgeschichte südostdeutschlands im Mittelalter (Veröffentlichungen des instituts für Geschichtsforschung und Archivwissenschaft in Wien, Baden bei Wien, $1939^{1}, 1942^{2}, 1943^{3}, 1959^{4}$. . Hay edición italiana como Terra e potere. Structure pre-statali e pre-moderne nella storia costituzionale dell'Austria medievale (Milano, 1983). También hay traducción inglesa, bajo el título Land and Lordschip: Structutes of Governance in Medieval Austria (con prefacio de Howard Kaminsky y James van Horn Melton Philadelphia, 1992). Cabría decir que esta obra es contemporánea de la magnífica The Roman Revolution de Ronald Syme de 1939.

${ }^{42}$ Libro II. 
sobre el "Land" 43 , adentrándose en los valores esenciales del hombre medieval germánico -el derecho a la venganza, el honor, la fidelidad, etc. ${ }^{44}$-, herederos de aquel pasado en el que el pueblo ("das Volk") veía el derecho como "justicia” o "equidad” ("Gerechtigkeit”) subjetiva. Desde la época germánica hasta la Edad Media, los germanos reunidos en torno a esos valores fundamentales, organizaron históricamente su propio sistema político-social de existencia bajo la forma de un territorio ("Land"), antes que el estado moderno. Haciendo un trabajo de exhumación de aquellos valores germánicos sobre los que fundaba históricamente la "Verfassung" germánica y medieval alemana, se encontrarían las raíces de la Alemania que el régimen nacionalsocialista buscaba reinstaurar. El sentido profundo del libro de Brunner se encuentra en su conclusión: se trata de restablecer en su autenticidad la organización social, la "konkrete Ordnung", de la Edad Media y sus raíces germánicas ${ }^{45}$. La obra, pues, como señala Jean-Marie Moeglin, es un requisito necesario para comprender la profunda legitimidad histórica de la empresa de restauración de las verdaderas estructuras de la vida germánica que el Estado hitleriano se propuso, después de haber dejado caer el Estado liberal de la República de Weimar. En efecto, Brunner señala que lo germano antiguo tiene un lugar respetable, pero desaparecido, incluso superado por el pueblo alemán. Sin embargo, de todo ello quedaban algunos aspectos fundamentales que era necesario despertar. Pero el tiempo había hecho su parte, el mundo moderno y la industrialización crearon un nuevo orden, tapando esas realidades antiguas que constituían la excelencia del pueblo alemán. Los fundamentos del Tercer Reich, fundados en el pueblo mismo y su liderazgo, debían ser remitidos a las bases germánicas ${ }^{46}$.

La cientificidad del libro de Brunner puede ser puesta en duda. Las nociones fundamentales ("Grundbegriffe") que invoca son, en principio, escogidos en las fuentes de manera inductiva; además, los concibe como postulados sobre los que no puede cuestionarse su veracidad, tomándolos de las grandes obras de los historiadores de la "germanidad", Gustav Neckel o Otto Höfler. Y como entre los antiguos germanos y la Edad Media hay una continuidad que no podría po-

\footnotetext{
${ }^{43}$ Libros siguientes.

${ }_{44}$ "Treue, einer der wesentlichsten Grundbegriffe aller politisch-sozialen Ordnung germanistischer Art [...]": p. 179.

${ }^{45}$ Dicha conclusión va a desaparecer sin explicación en las ediciones posteriores a la tercera de 1943.

46 "Hier ist - so scheint es- das Germanische ein Stück einer zwar ehrwürdigen, aber längst entschwundenen, ja überwundenen Frühzeit unseres Volkes. Es wird nicht gefragt, wie weit germanische Grundgedanken heute noch lebendig sind oder neu zum Leben erweckt wurden. Gewiss, eine Rückkehr zu altgermanischen oder mittelalterlichen Formen ist unmöglich. Der Durchgang durch den modernen Staat prägt das Reich des deutschen Volkes ebensosehr wie dieses Volk angesichts der industriellen Grundlagen seines Lebens zwar dem Bauerntum einem neuen gesicherten Platz in der Volksordnung einräumen kann, nicht mehr jedoch in Verbänden, die "Land" schlechthin sind, zu leben vermag. Aber die politischen Grundbegriffe des Dritten Reiches, Führung und Volksgemeinschaft, sind letztlich nur germanischen Grundlagen zu verstehen. In diesem Zusammenhang mag auch einem zeitlich und räumlich beschränkten Stück der Verfassungsgeschichte des deutschen Mittelalters, wie wir es hier vorlegten, seine Bedeutung zukommen": p. 511-2.
} 
nerse en duda, con aquellos historiadores reconstruye la "Verfassung" medieval. El problema es que, por un lado, esta continuidad debe demostrarse, y por el otro, el rigor científico de los historiadores sobre los que se apoya está en franco entredicho ${ }^{47}$.

La obra se inicia con una sección dedicada a la paz y la faida ("Friede und Fehde), institución que, como hemos visto, había sido concebida como una simple manifestación de violencia, prejurídica. Señalando la importancia de la venganza, Brunner advierte que en la época germánica, ésta no debe inducirnos a pensar en el instinto desatado, sino un deber imperioso que todo hombre tiene de proteger su honor, una autodefensa. Se trata, pues, de una institución legal, por lo cual no debe considerarse como una simple irrupción sentimental o una irracional descarga instintiva, carente de ponderación y de límites ${ }^{48}$.

Brunner se esfuerza por no enjuiciar el fenómeno de la autodefensa con las categorías propias del positivismo jurídico, intrínsecamente racionalista, esto es, aplicar al análisis el dualismo del ser y el deber ser, sociedad y naturaleza, orden moral y orden natural. La mentalidad jurídica del cristianismo antiguo y medieval habría concebido el mundo como un todo indisoluble con la voluntad divina. Por ello, no puede explicarse que las pautas de comportamiento en la represión y la punición -venganza, expiación, enemistad, desafío, etc.- se hayan mantenido durante tanto tiempo, si se las presenta como manifestaciones emanadas solamente de la naturaleza, sin vincularlas a las realidades religiosas.

La mirada del estudioso debe abrirse a un espectro más amplio, donde la faida no se quede convertida en un residuo de barbarie germánica, una mera venganza de sangre ("Blutrache), sino que se conciba como la expresión de la libre voluntad que un individuo manifiesta de su derecho subjetivo a obtener reparación de las ofensas que le fueron inferidas. Esta realidad debe concebirse como una suerte de sustrato permanente -digamos, una "estructura"- a lo largo de toda la Edad Media, abarcando tanto la venganza de sangre como también la faida caballeresca ("Ritterfehde").

Hemos visto que el tema de la libertad personal del germano y la existencia del Estado lo había abordado antes tanto Rogge y Wilda. Pero siguiendo los anteriores planteamientos de Georg Waitz, Otto Brunner se opone radicalmente a la obra de Franz Beyerle. En realidad, éste se oponía a la tesis de la antigua escuela de Georg Wilda y Heinrich Brunner, que señalaba que la venganza sería una supervivencia de un estadio pre-social anterior a la existencia de Estado germánico y medieval, el cual la habría tolerado durante mucho tiempo, pero que se empeñó en perseguirla debido a que, ontológicamente, un Estado no puede coexistir con el ejercicio de la venganza privada.

Ciertamente, Otto Brunner les reconocía haber constatado la importancia de la faida en el Estado germánico originario y en la época medieval, pero les cuestionó

${ }^{47}$ Moeglin, Le droit de vengeance, cit. (n. 3), p. 142.

48 "Die Fehde ist nicht Ausdruck eines "nativistischen” Rache- oder Zerstörungstriebes sondern Kampf ums Recht, daher sind auch der Art der Fehdeführung Grenzen rechtlicher Art gesetzt, die nicht überschritten werden dürfen, soll es sich um rechte Fehde handeln": BRUNNER, Otto, Land und Herrschaft, cit. (n. 41), p. 96. 
dos asuntos: el primero, haberla estudiado solamente a través de las disposiciones que buscaban limitarla o abolirla, perspectiva con la cual no era posible comprender la importancia que, según él, aquella merecía. El segundo, haber integrado todo dentro de la teoría de la "Friedlosigkeit", la cual no sería más que una ficción intelectual, puesto que ella reposaba sobre la idea errada de diferenciar entre el derecho subjetivo y el derecho objetivo, distinción que jamás tuvo realidad en las realidades medievales germánicas. Lo que en realidad existió, dice Brunner, es una "conciencia de un derecho unitario" ("einheitliches Rechtsbewusstsein") que hace imposible oponer derecho subjetivo y derecho objetivo. Por tal razón, enfatizaba en que había que distinguir aquellos casos donde un individuo cometía un crimen que provocaba la venganza del conjunto de la comunidad preocupada de restablecer el orden sagrado que ese crimen había violado. La antigua escuela le denominó la "Friedlosigkeit absoluta". Pero había también otros casos, donde la acción del individuo desencadenaba una faida del grupo familiar, esto es, una "Friedlosigkeit relativa" 49 .

Apoyándose en Carl Schmitt, construye su propia teoría del orden jurídico medieval, el que denomina "konkrete Lebensordnung", "concreto orden vital", o "Gesamtzustand der politischen Einheit und Ordnung", "total realización de la unidad y orden políticos". En este orden, el derecho subjetivo del individuo a obtener reparación por las ofensas que ha sufrido, está solamente limitado por los lazos de ayuda y de fidelidad en los que está inserto ${ }^{50}$. Dicho “orden" de la faida se mantuvo a pesar de los infructuosos esfuerzos desplegados para hacerla desaparecer; y estos intentos no son indicadores de que asistimos a un cambio radical en la naturaleza del Estado, que pasaría ahora a constituirse en un Estado, digamos, moderno. Para Brunner, el derecho a la venganza, bajo la forma del derecho a la faida, fue un componente fundamental de la organización jurídico-social de la Edad Media germánica. Sin embargo, este derecho estaba restringido a aquellos que monopolizaban la posesión de la fuerza militar, herederos de los germanos libres, por lo cual tomó la forma de una faida caballeresca, la "Ritterfehde". Se trata de un privilegio en manos de los que controlaban el "Land", el país, razón por la cual los campesinos no podían ejercer el derecho a la venganza. La única forma jurídica de vindicación que podían disponer, era la venganza de sangre ("Blutrache"). Este derecho estaba, sin duda, encuadrado y limitado por el poder señorial de los feudales que imponían su "protección y amparo", "Schutz und Schirm”, a cambio de la fidelidad que les era debida.

En conclusión, siguiendo la huella de sus predecesores tan criticados, Brunner también quería encontrar en la germanidad original y en la Edad Media, las raíces del Estado ideal que deseaba instaurar. Así, pues, el germano medieval era el ancestro del burgués alemán decimonónico. Sin embargo, su visión de la germanidad era mucho menos organizada que la desarrollada por historiadores del siglo XIX.

\footnotetext{
${ }^{49}$ BRUNNER, Land und Herrschaft, cit. (n. 41), p. 43 ss.

${ }^{50}$ Moeglin, Le droit de vengeance, cit. (n. 3), p. 140.
} 


\section{CONCLUSION}

Es admirable la sorprendente teoría que los historiadores alemanes construyeron para analizar el embrión de la juridicidad medieval, cuya coherencia nos parece notable. Sin embargo, el problema que tenía dicha construcción teórica era su carácter artificial, unas categorías de análisis que no se correspondían bien con las pruebas documentales. En efecto, aun cuando citaban cuidadosamente las fuentes y analizaban cada una en detalle, al estudiarlas y tratar de entender los fundamentos de dicho orden jurídico, les aplicaron un marco teórico de interpretación desvinculado de la realidad; la clave de esta entelequia fue el concepto "Friedlosigkeit", que permitía pensar en la realidad de un Estado de Derecho con la existencia de la venganza. Quizás el único fundamento documental que parecía sostener la existencia de una "Friedlosigkeit", era un pasaje de la ley sálica que condenaba a los violadores de las sepulturas y les declaraba wargus ${ }^{51}$. La antigua escuela había traducido este vocablo por "lobo", y con ello veía claramente que la mejor definición de "fuera de la ley" o "friedlos", implicaba que el wargus habría de llevar la existencia de una bestia salvaje. Este postulado teórico tuvo tal impacto y fue recibido con tanto prestigio, que durante mucho tiempo no se consideró necesario verificarlo documentalmente, con lo cual la vigencia de la "Friedlosigkeit" llegó hasta 1979. Ese año, dos trabajos importantes de Hermann Nehlsen y de Ekkerhard Kaufmann terminaron con el reinado de la "Friedlosigkeit" $"$. Este último, demostró brillantemente que el pasaje antes citado de la ley sálica derivaba directamente del derecho romano, y wargus significaba simplemente "bandido".

Los autores alemanes pensaron la sociedad tardo-antigua o altomedieval intentando conciliar la violencia proveniente del derecho subjetivo de toda persona y de su familia a obtener justa reparación y venganza con la existencia de un orden jurídico objetivo creando la paz común. Además, se preocuparon de dotar de un soporte legal al derecho a la venganza, y con ello no poner en cuestionamiento los fundamentos de la sociedad. De este esfuerzo surge la "Friedlosigkeit", que permitía conciliar en la sociedad germánica "ordnung und Konflikt", paz y conflicto, conceptos claves que actualmente estudia una importante corriente de la medievística denominada "the settlements of disputes" ${ }^{53}$. A ello, ha de agregarse

${ }^{51}$ Lex Salica, XVIII, $55 \$ 4$ (ed. Karl August Eckhard, Weimar, H. Böhlaus, 1953), p. 134. "Si quis corpus sepultum exfodierit et expoliaverit, wargus sit, id est expellis set, usque in diem illum, quam ipsa causa cum parentibus defuncti faciat emendare et ipsi parentis rogare ad judicem debeant, ut ei inter hominess liciat habitare".

${ }^{52}$ NeHLSEN, Hermann, Entstehung des öffentlischen Strafrecht bei den germanischen Stämmen, en Kroeschell, Karl (editor), Gerichslaubenvorträge, Festkoll. z. 75. Geburtstag v. Hans Thieme (Sigmarigen, 1983), pp. 3-16; KAUfMANn, Ekkerhard, Zur Lehre von der Friedlosigkeit im Germanischen Recht, en Beiträge zur Rechtsgeschichte. Gedächtnisschrift f. H. Conrad (Paderborn, 1979), pp. 329-332.

${ }^{53}$ BARTHÉLEMY, Dominique, La vengeance, le jugement et le compromis, en Actes des congrès de la Société des historiens médiévistes de l'enseignement supérieur public. $31^{e}$ congrès (Angers, 2000), pp. 13 ss. Véanse: Evans-Pritchard, Edward, The Nuer. A description of the modes of livelhood and political institutions of nilotic people (Oxford, 1940); BOURDIEU, Pierre, Le sens de l'honneur, 
que estos procedimientos pacíficos y bélicos de resolución de conflictos - a priori contradictorios- deben ser tenidos como un orden jurídico en sí mismo, desde luego peculiar, que no se limita a la judicatura, como lo había dicho K. A. Rogge, sino más la integra. La lección era abrirse a la existencia de un orden jurídico diverso, que acogía y prolongaba tradiciones jurídicas coherentes pero también contradictorias.

Una vez aceptado el derecho a la violencia privada, considerada lícita y legal, los intelectuales alemanes elaboraron una descripción en cierto modo etnográfica del ejercicio de la venganza. La virtud de esta empresa consiste en haber integrado la venganza dentro de un sistema de valores complejo, donde puede y debe ser comprendida. Mostraron, además, que la venganza se desarrollaba enmarcada por normas específicas que la alejaban de la violencia desatada e irracional. La distinción de los crímenes contra la comunidad, constituye otro aporte destacable, basamento que permitía proceder a la eliminación del culpable, ya que la existencia de la comunidad entera estaba en peligro.

\section{BiBLIOGRAFÍA}

Althoff, Gerd, Spielregeln der Politik im Mittelalter. Kommunikation in Frieden und Fehde (Darmstadt, Primus Verlag, 1997).

Amira, K. von, Die Germanischen Todesstrafen. Untersuchungen zur Rechts- und Religionsgeschichte (München, Abhandlungen der Bayerischen Akademie der Wissenschaften- Philosophisch- philologiche und historische Klasse, XXXI, 3, 1922).

BARTHÉLEMY, Dominique, La vengeance, le jugement et le compromis, en Actes des congrès de la Société des historiens médiévistes de l'enseignement supérieur public. $31^{e}$ congrès (Angers, 2000).

BEYERLE, F., Das Entwicklungsproblem im germanischen Rechtsgang, I: Sühne, Rache und Preisgabe in ihrer Beziehung zum Strafprozess der Volksrechte (Heidelberg, 1915).

BongerT, Yvonne, Recherches sur les cours lä̈ques du Xe au XIII' siècle (Paris, 1944).

Bossy, John (editor), Disputes and Settlements. Law and Human Relations in West (Cambridge, 1983).

Bourdieu, Pierre, Le sens de l'honneur, en Esquisse d'une théorie de la pratique (Genève, 1972).

Brown, Peter, Society and the Supernatural: a Medieval Change, en Daedalus, 104 (1975).

Brunner, H., Sippe und Wergeld nach niederdeutschen Reichen, en Zeitschrift der Savigny-Stiftung für Rechtsgeschichte, germ. Abt., 3 (1882).

en Esquisse d'une théorie de la pratique (Genève, 1972), pp. 15-43; Brown, Peter, Society and the Supernatural: a Medieval Change, en Daedalus, 104 (1975), pp. 131-151; Miller, William, Bloodtaking and Peacemaking. Feud, Law and Society in Saga Iceland (Chicago-Londres, 1990); Bossy, John (editor), Disputes and Settlements. Law and Human Relations in West (Cambridge, 1983). Véase la bibliografía sobre los "anthropologist lawyers": GEARY, Patrick, Vivre en conflit dans une France sans Etat: tipologie des mécanismes de règlement des conflicts, en Annales ESC. (1986), pp. 1107-1133; Althoff, Gerd, Spielregeln der Politik im Mittelalter. Kommunikation in Frieden und Fehde (Darmstadt Primus, 1997). 
Brunner, H., Deutsche Rechtsgeschichte (Leipzig, 1887).

BRUnNer, H., Deutsche Rechtsgeschichte (München-Leipzig, 1928).

Brunner, H., Die Abspaltungen der Friedlosigkeit, en Zetschrift der Savigny-Stiftung für Rechtsgeschichte, germ. Abt., 11 (1890).

BRUNNER, O., Land und Herrschaft. Grundfragen der territorialen Verfassungsgeschichte südostdeutschlands im Mittelalter (Veröffentlichungen des instituts für Geschichtsforschung und Archivwissenschaft in Wien, Baden bei Wien, 1939 ${ }^{1}, 1942^{2}$, $1943^{3}, 1959^{4}$.

Dilcher, G. - Kern, B. R., Die juristische Germanistik des 19. Jahrhunderts und die Fachtradition der Deutschen Rechtsgeschichte, en Zeitschrift für Rechtsgeschischte, germ. Abt., 101 (1984).

DuBY, Georges, Recherches sur l'évolution des institutions judiciaires pendants le $X^{e}$ et le XI siècle dans le Sud de la Bourgogne, en Le Moyen Âge, 52 (1946); 53 (1947).

Ducoudray, Gustave, Les origines du Parlement de Paris et la Justice aux XIII'-XIV siècles (Paris, 1902).

EICHhorn, K. F., Deutsche Staats- und Rechtsgeschichte (Gottigen, 18425-1844).

ERLER, A., Handwörterbuch zur deutschen Rechtsgeschichte, V.

Evans-Pritchard, Edward, The Nuer. A Description of the Modes of Livelhood and Political Institutions of Nilotic People (Oxford, 1940).

GeArY, Patrick, Vivre en conflit dans une France sans Etat: tipologie des mécanismes de règlement des conflicts, en Annales, ESC. (1986).

Glasson, Ernest, Histoire du droit et des institutions de la France (Paris, 1888).

GuIzot, François, Cours d'histoire moderne. Histoire de la civilisation en France depuis la chute de l'Empire romain jusqu'en 1789 (Paris, 1829-1832), 5 vols.

Kaufmann, E., Zur Lehre von der Friedlosigkeit im Germanischen Recht, en Beiträge zur Rechtsgeschichte. Gedächtnisschrift f. H. Conrad (Paderborn, 1979).

KROESCHELL, Karl, Germania in der deutschen Rechts-und Verfassungsgeschichte, reeditado en Studien zum frühen und mittelalterlichen Recht (Berlin, 1995).

MilLer, William, Bloodtaking and Peacemaking. Feud, Law and Society in Saga Iceland (Chicago -Londres, 1990).

MOEGLIN, Jean-Marie., Le droit de vengeance chez les historiens du droit au Moyen $\hat{A} g e\left(X I X^{e}-X X^{e}\right.$ siècles), en D. BARTHÉLEMY - F. BOUGARD - R. JAN (directores.), La vengeance 400-1200 (École Française de Rome, 2006).

Monod, Gabriel, Les aventures de Sichaire, en Revue Historique, 31 (1886).

NeHLSEN VON STRYK, Karin, Zum “justizbegriff” der rechtshistorischen Germanistik, en Ius commune, 17 (Frankfurt a. M., 1990).

NeHLSEN, H., Entstehung des öffentlischen Strafrecht bei den germanischen Stämmen, en Kroeschell, K. (editor), Gerichslaubenvorträge, Festkoll. Z. 75. Geburtstag v. Hans Thieme (Sigmarigen, 1983).

PetiT-Dutaillis, Charles, Documents nouveaux sur les mours populaires et le droit de vengeance dans les Pays Bas du XV siècle, Paris, 1908 (reimpr., en Slatkine Reprints, Genève, 1975).

Rogge, K. A, Über das Gerichtswessen der Germanen. Ein Germanistischer Versuch (Halle, 1820).

SAvignY, Friedrich Karl von, Über den Beruf unserer Zeit für Gesetzgebung und Rechtswissenschaft (Berlin, 1814).

SCHWERING, C., reseña en Zeitschrift der Savigny-Stiftung für Rechtsgeschichte, germ. Abt., 36 (1915). 
THiBaut, August, Über die Nothwendigkeit eines allgemeinen bürgerlichen Rechts für Deutschland (Berlin, 1814).

WaItZ, G., Deutsche Verfassungsgeschichte (1ª edición, Kiel 1844-78; $2^{\text {a }}$ edición, 186570; 3a edición, 1880-1896; 4a edición 1953).

WILDA, W. E., Das Strafrecht der Germanen (Halle, 1842; reimpresiòn Aalen, 1960). 
